\title{
Analysis of maternal effects on development in mammals
}

\author{
Anne McLaren \\ M.R.C. Mammalian Development Unit, Wolfson House, 4 Stephenson Way, \\ London NWI $2 H E$, U.K.
}

\section{Introduction}

The traditional definition of a maternal effect, which I shall adopt, involves any influence of a mother on her offspring exerted otherwise than by direct transmission of nuclear genes. The influence may be exerted through the cytoplasm of the egg, in which case it would be determined before ovulation, or through the reproductive tract, reflecting aspects of the maternal physiology during gestation, or after birth, through lactation or some other aspect of child rearing. Whether it is cytoplasmic, or exerted through the reproductive tract, or after birth, the source of the maternal effect may lie in the mother's genetic constitution or may involve some environmental factor, which could of course include the environment to which the mother herself was exposed.

Paternal effects, similarly defined, may be exerted either through non-chromosomal sperm components, or post-natally, in the course of child-rearing. They are less common than maternal effects, both because the nucleus constitutes a larger proportion of the gamete in the male than in the female, and because in most species a larger proportion of child-rearing is done by the mother than by the father. They fall outside the scope of this paper.

\section{Postnatal effects}

Maternal effects do not necessarily lead to offspring resembling their mothers more than their fathers. With respect to IQ scores, human children show no greater resemblance to their mothers than to their fathers (McAskie \& Clarke, 1976), yet for verbal IQ, defined by psychologists as the ability to do well in verbal IQ tests, a maternal effect has recently been demonstrated. Rose $e t$ al. (1980) showed that, when subjected to such tests, the children of monozygotic twin sisters resembled each other significantly more than did the children of monozygotic twin brothers. Genetically, children of monozygotic twins are half-siblings; they make a better basis for comparison than do conventional half-siblings, because the sibships have the same expected age and size.

The female twin pairs themselves did not resemble one another in verbal IQ any more closely than did the male twin pairs, nor were their husbands any more similar to one another than were the wives of the twin brothers. The higher correlations between the scores of the children of the twin sisters therefore bear witness to the existence of a maternal effect. This may have been exerted post-natally, through the more similar patterns of child-rearing that monozygotic twin sisters might provide, or it may reflect a similarity in intrauterine environment.

Prenatal and postnatal effects can in principle be distinguished by cross-fostering studies, although there are obvious problems in applying such a method in man. The classic example involves incidence of mammary tumours in mice. Inbred strains vary with respect to tumour 
incidence; when reciprocal crosses between high and low strains are carried out, the incidence in the $F_{1}$ generation resembles that in the maternal strain. Cross-fostering experiments established that the maternal effect was exerted after birth, and further studies showed the existence of a mammary tumour virus transmitted through the milk (for references, see Grüneberg, 1952). A similar milk effect may turn out to underlie the two-generation maternal effect on lymphoma resistance recently reported by Mayer, Struuck, Duran-Reynals \& Lilly (1980). Cross-fostering studies have also emphasized the importance of postnatal maternal influences on growth in large and small strains of mice (Young, Legates \& Farthing, 1965; Moore, Eisen \& Ulberg, 1970).

\section{Prenatal effects}

Another obvious method of distinguishing prenatal from postnatal influence is to see whether an effect can already be detected at birth. Maternal effects on body weight are common; since these often show up in the analysis of birth weight, a prenatal component must exist. In our own species, a maternal effect on birth weight has been demonstrated by Robson (1955), who showed that babies born to sisters were significantly more similar to one another in birth weight than were the babies of brothers, or brother and sister; and similar effects have been teported in other species (see below).

The next step in analysis is to ask at what stage a prenatal maternal effect is exerted, and in particular whether it operates through the cytoplasm of the egg or through the mother's reproductive tract. The experimental techniques appropriate for this purpose (see McLaren, 1962) are transfer of embryos or unfertilized eggs, and transplantation of ovaries. Again the application to our own species presents problems, but since embryo transfer has established that maternal effects on birth weight are exerted during intrauterine life in mice (Brumby, 1960; Moore et al., 1970; Al-Murrani \& Roberts, 1978), rabbits (Venge, 1950) and sheep (Hunter, 1956), it seems likely that the same route operates in women also.

Not only weight, but also anatomical characters not correlated with size, may be affected by the maternal environment provided during gestation. In mice, the number of lumbar vertebrae varies among different inbred strains, and the $F_{1}$ progeny of reciprocal crosses tend to resemble the maternal strain. McLaren \& Michie (1958) showed that mice developing from reciprocally transferred embryos resembled their foster mothers rather than their genetic mothers with respect to number of lumbar vertebrae, thus establishing that the maternal effect was exerted through the uterus rather than through the egg cytoplasm.

These maternal effects on birth weight and vertebral type are controlled by genetic factors present in the uterine foster mother, though they may also be influenced by the environment to which she has been exposed. Other genetically derived maternal effects which still await analysis by embryo transfer include some striking effects on the penetrance and expression of genes in the progeny. Tabby mice resemble their mothers rather than their fathers with respect to whisker number (Kindred, 1961); for the incompletely penetrant gene Fused, more of the young are affected if the mother is phenotypically normal than if she herself is affected (Reed, 1937); with an agouti locus gene (viable yellow) that produces a variable phenotypic effect, ranging from yellow to agouti, the phenotype of the young depends on the genotype of the mother in reciprocal crosses, and also on the phenotype of the mother, but not at all on the phenotype of the father (Wolff, 1978).

\section{Environmental insults}

A similar type of analysis can be applied to maternal effects that are environmental in origin, whether the environmental stimulus is a chronic one, such as a long-term dietary deficiency or 
hormonal disturbance, or acute, such as a single exposure to drugs, irradiation or infective agents.

In the case of an acute environmental insult, the time of action of the maternal effect is likely to coincide with the time of exposure, but this is not necessarily so. Embryo transfer may be used both to ascertain whether the effect is exerted before transfer or after, and also to determine whether the environmental agent is acting by way of the maternal physiology, or directly on the embryo. High ambient temperature during the first 6 days of pregnancy causes increased embryonic mortality in rabbits: Shah (1956) carried out reciprocal embryo transfer between mothers kept at high temperatures and at normal temperatures during this period, and showed that the adverse effects of the heat were exerted through the uterine environment, subsequent to the initial 6-day period when the heat stress was applied.

Often the effect on the embryo depends critically on the stage of gestation at which the environmental stimulus occurs. A recent example was reported by Seller, Embury, Polani \& Adinolf (1979). The progeny of curly-tail mice show a high incidence of neurovertebral defects, analogous to neural tube defects in man (Embury, Seller, Adinolfi \& Polani, 1979); when vitamin A, a known teratogen for the central nervous system, was injected on the 9th day of pregnancy the number of affected young was increased, but on the 10th day the same dose of vitamin A decreased the incidence below that found in untreated litters. This effect is particularly intriguing in view of the suggestion that vitamin supplements may reduce the risk of neural tube defects in human pregnancy (Smithells et al., 1980). The teratogenic effect of vitamin A on the 9th day of pregnancy was also shown in mice of the Strong A strain, which have no spontaneous incidence of neurovertebral defects, but the effective dose was very much higher than in mice of the curly tail strain. Although the incidence of defect could thus be increased by manipulation of the maternal physiology, the difference between the two strains in spontaneous incidence was not a maternal effect, or at least not one mediated through the uterine environment, since curly tail embryos were shown by transfer studies to be equally prone to neurovertebral defects whether they were gestated in a curly tail or a Strong A uterus (M. J. Seller \& M. Adinolfi, personal communication).

In our next example the maternal effect is again exerted through the uterine environment, but now stems from the mother's genetic constitution. The mode of action of the relevant gene is known and can be reproduced in geneticaly normal females by dietary manipulation, so as to produce an exact phenocopy of the maternal effect, environmental rather than genetic in origin. A strain of mice showing abnormalities of behaviour due to lesions of the inner ear proved to lack the enzyme histidase and hence to have very high levels of plasma histidine (Kacser, Bulfield \& Wallace, 1973). Genetic analysis showed that a single autosomal recessive, histidinaemia (his), was responsible for the biochemical defect, and reciprocal crosses between histidinaemic and normal mice established that the inner ear lesions were due to a maternal effect. Only homozygous his/his mothers exerted the effect; the genotype of the father was irrelevant; and lesions could be induced even in $+/+$ embryos by transfer to a his/his uterus (Kacser et al., 1977). Similar behavioural defects could be produced in the progeny of genetically normal females if the maternal plasma histidine levels were increased by dietary supplements, provided these were given during the second week of pregnancy; and the maternal effect could be prevented in his/his females by feeding them a low histidine diet (Kacser, Khin \& Bulfield, 1979). The parallel to the maternal effect exerted in human phenylketonuria (Denniston, 1963), which can lead to mental retardation in children themselves metabolically normal, is obvious. In mice, there is genetic variation in susceptibility to the effects of maternal histidinaemia, and this genetic variation does not show any maternal effect (Kacser et al., 1979).

The numerous teratogenic agents that can exert their effects through the maternal physiology will not be considered further, as they have been well reviewed by Morriss (1979) and are discussed by Kaufman (1981). 


\section{Cytoplasmic influences}

There is, however, one example of a response to a teratogen which is itself subject to a maternal effect that may prove to be mediated through the cytoplasm of the egg, or at least the egg mitochondria, rather than the uterine environment. The situation is again complex. On one diet, though not on another, two inbred strains of mice showed a difference in the frequency of cleft palate after treatment with 6-amino-nicotinamide (Verrusio, Pollard \& Fraser, 1968). Reciprocal crosses gave evidence of a maternal effect, in that the $F_{1}$ embryos resembled the maternal strain in susceptibility, and this difference persisted into the next generation when the two types of $F_{1}$ females were backcrossed to one of the parental strains. A maternal effect exerted through the uterine environment and transmitted over more than one generation is in principle possible, if the uterine environment not only produces the maternal effect but also modifies the physiology of the female embryos in such a way as to alter the uterine environment that they will in turn provide for their embryos. Verrusio et al. (1968), however, prefer an alternative hypothesis, namely that the variation in response to 6-amino-nicotinamide is due to a genetically determined difference in mitochondria, since 6-amino-nicotinamide is known to form an inactive analogue that interferes with oxidative phosphorylation in mitochondria. Along with other cytoplasmic components, mitochondria are thought to be largely if not entirely inherited from the mother, since paternal variants could not be detected in the progeny of interspecific (Hutchison, Newbold, Potter \& Edgell, 1974) or intraspecific (Buzzo, Fouts \& Wolstenholme, 1978 ) crosses. Which of the two hypotheses is correct could again be analysed by embryo transfer or ovary transplantation, but this has so far not been done.

Only one maternal effect has as yet been analysed by ovary transplantation. Females of the Japanese mouse strain DDK have litters of 7-8 young if mated to males of their own strain, but very small litters (less than one live born) if outcrossed, since most of the hybrid embryos die at around the time of implantation. Reciprocal crosses, with DDK fathers, show good embryo survival. To distinguish between a cytoplasmic effect and an incompatibility between the hybrid embryo and the environment provided by the DDK oviduct, Wakasugi (1973) grafted DDK ovaries into hybrid females. The DDK eggs, when fertilized by spermatozoa of a different strain, still failed to survive implantation. The incompatibility evidently operates between the egg cytoplasm and the alien spermatozoon. As a result of subsequent genetic analysis, Wakasugi (1974) postulates a locus, ovum mutant $(\mathrm{om})$, at which the normal allele $O M$ produces a cytoplasmic substance $O$ that has to interact with a sperm gene product, $\mathrm{S}$ or $\mathrm{s}$, coded by the same or a closely linked locus, if development is to succeed. In the DDK strain, a recessive allele om produces a variant substance $o$, which interacts successfully with mutant sperm $s$, but is incompatible with $\mathrm{S}$. The biochemical nature of $\mathrm{O}$ and $\mathrm{S}$ remains obscure.

That there should be cytoplasmic effects on development is hardly surprising, since the ovulated egg contains about $25 \mathrm{ng}$ protein and a total of $500 \mathrm{pg}$ RNA, including more than enough messenger RNA to programme all the egg ribosomes. On the other hand one would expect any such effects to show up early in development, since the embryo's own genome is active by mid-cleavage (see McLaren, 1976, 1979; Sherman, 1979). There is little or no evidence for the persistence of maternal gene products transmitted through the cytoplasm after the blastocyst stage. Good evidence for the importance of such maternal gene products up to the 8-cell stage comes from studies of XO mice: since in normal XX females both X chromosomes are active during oogenesis, $\mathrm{X}$-coded enzyme activity is halved in eggs produced by XO females, and this relative enzyme deficiency persists to the 8-cell stage, even though the level of enzyme activity is increasing rapidly (Monk \& Harper, 1978). Embryos from XO females have a high failure rate during the preimplantation period, a maternal effect that must be mediated by the egg cytoplasm rather than the oviduct environment, because it is still present under conditions of in-vitro culture (Burgoyne \& Biggers, 1976). 


\section{Follicular environment}

As more studies on early embryos of different genetic strains are undertaken, more such cytoplasmic effects are likely to be uncovered. One further analytical step is required. Of the 25 ng protein present in the ovulated egg, only about $50 \%$ can have been synthesized within the oocyte, if indeed recent recent estimates of the rate of protein synthesis and the time available are correct (Schultz, Letourneau \& Wassarman, 1979). The remaining 50\% must have been taken in from the surrounding follicle. A maternal effect on egg phenotype or on early embryonic development may therefore be mediated either by the egg's own genes or by the follicular environment.

In a mouse chimaera, an oocyte of one genotype will be surrounded by a multicellular follicle probably containing a mixture of cells of the two component genotypes, in which one may predominate. Individual follicles can be isolated, the proportions of the two components represented in the follicle cells can be determined by enzyme analysis, and the phenotype or development potential of the egg can be examined. We have used female chimaeras betwen the $\mathrm{C} 57 \mathrm{BL}$ and $\mathrm{BALB} / \mathrm{c}$ inbred strains to look in this way at 3 egg characteristics that differ in the component strains (A. McLaren \& M. Buehr, unpublished observations). The cytoplasm of C57BL eggs contains dark lipid granules, while BALB/c cytoplasm is clear; the enzyme glucose phosphate isomerase (GPI) shows very low activity in BALB/c eggs, while in C57BL eggs the activity is as high as in somatic tissues; the two strains differ in GPI isoenzyme type. All eggs examined proved to be either C57BL or BALB/c in phenotype, on all 3 criteria, irrespective of whether the follicie in which they had developed was made up predominantly of cells of the same or of contrasting genotype. We are at present using a similar approach to try to analyse the DDK cytoplasmic effect.

\section{Conclusions}

To summarize, we have seen that maternal effects of environmental origin can be identified by exposure of females to chronic or acute environmental stimuli, while maternal effects of genetic origin can be detected by reciprocal crosses between inbred strains, by the genetically equivalent half-sib analysis, or by less powerful procedures such as cousin analysis. Maternal effects may be exerted after birth, or during gestation via the uterine or the oviduct environment, or before ovulation via the cytoplasm of the egg. These various possibilities can be distinguished by a combination of techniques, including cross-fostering, transfer of embryos or unfertilized eggs, in-vitro culture, and transplantation of ovaries. The source of a cytoplasmic agent, whether synthesized within the oocyte or transmitted from the follicular environment, can be determined by ovarian follicle analysis in chimaeras.

\section{References}

Al-Murrani, W.K. \& Roberts, R.C. (1978) Maternal effects on body weight in mice selected for large and small size. Genet. Res. 32, 295-302.

Brumby, P.J. (1960) The influence of the maternal environment on growth in mice. Heredity 14, 1-18.

Burgoyne, P.S. \& Biggers, J.D. (1976) The consequences of $\mathrm{X}$-dosage deficiency in the germ line: impaired development in vitro of preimplantation embryos from XO mice. Devl Biol. 51, 109-117.

Buzzo, K., Fouts, D.L. \& Wolstenholme, D.R. (1978) Eco $\mathrm{R} 1$ cleavage site variants of mitochondria DNA molecules from rats. Proc. natn. Acad. Sci. U.S.A. 75, 909-913.

Denniston, J.C. (1963) Children of mothers with phenylketonuria. J. Pediat. 63, 461-462.
Embury, S., Seller, M.J., Adinolf, M. \& Polani, P.E. (1979) Neural tube defects in curly-tail mice. I. Incidence, expression and similarity to the human condition. Proc. R. Soc. Lond. B 206, 85-94.

Grüneberg, H. (1952) The Genetics of the Mouse, 2nd edn. Martinus Nijhoff, The Hague.

Hunter, G.L. (1956) The maternal influence on size in sheep. J. agric. Sci., Camb. 48, 36-60.

Hutchison, C.A., Newbold, J.E., Potter, S.S. \& Edgell, M.H. (1974) Maternal inheritance of mammalian mitochondrial DNA. Nature, Lond. 251, 536.. 538.

Kacser, H., Bulfield, G. \& Wallace, M.E. (1973) Histidinaemic mutant in the mouse. Nature, Lond. 244, 77-79. 
Kacser, H., Khin, M.M. Duncker, M., Wright, A.F., Bulfield, G., Lyon, M. \& McLaren, A. (1977) Maternal histidine metabolism and its effect on foetal development in the mouse. Nature, Lond. 265, 262-266.

Kacser, H., Khin, M.M. \& Bulfield, G. (1979) Endogenous teratogenesis in maternal histidinaemia. In Models for the Study of Inborn Errors of Metabolism, pp. 43-53. Ed. F. A. Hommes. Elsevier: North-Holland Biochemical Press, Amsterdam.

Kaufman, M.H. (1981) The role of embryology in teratological research with particular reference to the development of the neural tube and heart. J. Reprod. Fert. 62, 607-623.

Kindred, B.M. (1961) A maternal effect on vibrissae score due to the Tabby gene. Aust. J. biol. Sci. 14, 627-636.

Mayer, A., Struuck, F.D., Duran-Reynals, M.L. \& Lilly, F. (1980) Maternally transmitted resistance to lymphoma development in mice of reciprocal crosses of the RF/J and AKR/J strains. Cell 19, 431-436.

McAskie, M. \& Clarke, A.M. (1976) Parent-offspring resemblances in intelligence: theories and evidence. Br.J. Psychol. 67, 243-273.

McLaren, A. (1962) Maternal effects in mammals and their experimental analysis. In Proc. 1st Int. Conf. on Congenital Malformations, pp. 211-222. Ed. M. Fishbein. Lippincott, Philadelphia.

McLaren, A. (1976) Genetics of the early mouse embryo. Ann. Rev. Genet. 10, 361-388.

McLaren, A. (1979) The impact of pre-fertilization events on post-fertilization development in mammos. In Maternal Effects in Development, pp. 287-320. Eds D. R. Newth \& M. Balls. Cambridge University Press.

McLaren, A. \& Michie, D. (1958) Factors affecting vertebral variation in mice. IV. Experimental proof of the uterine basis of a maternal effect. J. Embryol. exp. Morph. 6, 645-659.

Monk, M. \& Harper, M. (1978) X-chromosome activity in preimplantation embryos from $\mathrm{XX}$ and $\mathrm{XO}$ mothers. J. Embryol. exp. Morph. 46, 53-64.

Moore, R.W., Eisen, E.J. \& Ulberg, L.C. (1970) Prenatal and postnatal maternal influences on growth in mice selected for body weight. Genetics, Princeton 64, 59-68.

Morriss, G.M. (1979) Teratogenesis. In Maternal Effects in Development, pp. 351-373. Eds D. R. Newth \& M. Balls. Cambridge University Press.

Reed, S.C. (1937) The inheritance and expression of Fused, a new mutation in the house mouse. Genetics, Princeton 22, 1-13.
Robson, E.B. (1955) Birth weight in cousins. Ann. Hum. Genet. 19, 262-268.

Rose, R.J., Boughman, J.A., Corey, L.A., Nance, W.E., Christian, J.C. \& Kang, K.W. (1980) Data from kinships of monozygotic twins indicate maternal effects on verbal intelligence. Nature, Lond. 283, 375-377.

Schultz, R.M., Letourneau, G.E. \& Wassarman, P.M. (1979) Program of early development in the mammal: changes in the pattern and absolute rates of tubulin and total protein synthesis during oocyte growth in the mouse. Devl Biol. 73, 120-133.

Seller, M.J., Embury, S., Polani, P.E. \& Adinolfi, M. (1979) Neural tube defects in curly-tail mice II. Effect of maternal administration of vitamin A. Proc. $R$. Soc. Lond. B 206, 95-107.

Shah, M.K. (1956) Reciprocal egg transplantations to study the embryo-uterine relationship in heat-induced failure of pregnancy in rabbits. Nature, Lond. 177, 1134-1135.

Sherman, M. (1979) Developmental biochemistry of preimplantation mammalian embryos. Ann. Rev. Biochem. 48, 443-470.

Smithells, R.W., Sheppard, S., Schorah, C.J., Seller, M.J., Nevin, N.C., Harris, R., Read, A.P. \& Fielding, D.W. (1980) Possible prevention of neural-tube defects by periconceptional vitamin supplementation. Lancet i, 339-340.

Venge, O. (1950) Studies of the maternal influence on the birth weight in rabbits. Acta zool. 31, 1-148.

Verrusio, A.C., Pollard, D.R. \& Fraser, F.C. (1968) A cytoplasmically transmitted, diet-dependent difference in response to the teratogenic effect of 6-aminonicotinamide. Science, N.Y. 160, 206-207.

Wakasugi, N. (1973) Studies on fertility of DDK mice: reciprocal crosses between $\mathrm{DDK}$ and $\mathrm{C} 57 \mathrm{BL} / 6 \mathrm{~J}$ strains and experimental transplantation of the ovary. J. Reprod. Fert. 53, 283-291.

Wakasugi, N. (1974) A genetically determined incompatibility system between spermatozoa and eggs leading to embryonic death in mice. J. Reprod. Fert. 41, 85-96.

Wolff, G.L. (1978) Influence of maternal phenotype on metabolic differentiation of agouti locus mutants in the mouse. Genetics, Princeton 88, 529-539.

Young, C.W., Legates, J.E. \& Farthing, B.R. (1965) Prenatal and postnatal influences on growth, prolificacy and maternal performance in mice. Genetics, Princeton 52, 553-561. 